Volume 11

Issue 1 Winter 2018

Article 8

2018

\title{
A Few Reflections on A Numerate Life
}

John Allen Paulos

Temple University, math233@gmail.com

Follow this and additional works at: https://digitalcommons.usf.edu/numeracy

Part of the Mathematics Commons

\section{Recommended Citation}

Paulos, John A.. "A Few Reflections on A Numerate Life." Numeracy 11, Iss. 1 (2018): Article 8. DOI: https://doi.org/10.5038/1936-4660.11.1.8 


\title{
A Few Reflections on A Numerate Life
}

\author{
Abstract \\ John Allen Paulos. 2015. A Numerate Life: A Mathematician Explores the Vagaries of Life, His Own and \\ Probably Yours (Amherst, NY: Prometheus Books). 200 pp. ISBN 978-1633881181. \\ This piece briefly introduces and excerpts $A$ Numerate Life: $A$ Mathematician Explores the Vagaries of \\ Life, His Own and Probably Yours, written by John Allen Paulos and published by Prometheus Books. The \\ book shares observations on life-many biographical-from the perspective of a numerate \\ mathematician. The excerpt uses basic statistical reasoning to explore why we should expect that being \\ odd is a most normal experience. \\ Creative Commons License \\ (c) (1) \& \\ This work is licensed under a Creative Commons Attribution-Noncommercial 4.0 License \\ Cover Page Footnote \\ John Allen Paulos is Professor of Mathematics at Temple University and the author Innumeracy, $A$ \\ Mathematician Reads the Newspaper, and, most recently, A Numerate Life among other books. His web \\ page is johnallenpaulos.com and his twitter feed is twitter.com@johnallenpaulos
}




\section{Author's Reflections: A Numerate Life}

Lawyers, journalists, economists, novelists, and "public intellectuals," among others, are all frequent commentators on both contemporary social issues and our personal lives and predicaments. And as someone who majored at one time or another in English, classics, and philosophy, I say rightly so, but I still bemoan the fact that scientists and especially mathematicians are not on this list.

People often pay lip service, of course, to the importance of mathematics and sometimes even express an undue reverence for mathematicians, but these attitudes are usually accompanied by a casual dismissal of the subject and its practitioners as irrelevant to matters of real importance. Mathematics is deemed esoteric and outside the ongoing public and private narratives and conversations that surround us. If mentioned in a general context, it is usually used to provide decoration, rather than information.

As I've tried to argue in several of my books, these attitudes are profoundly wrong. They seem compelling, however, because of still rampant innumeracy, which prompts people with little or no mathematical background to view mathematicians' remarks and insights as always either completely trivial or forbiddingly abstract or else beside the point. Of course, these traits characterize many of the remarks of more traditional commentators, but here the remarks' familiarity disguises their irrelevant banality. How many times do painfully fatuous points get repeated day after day by TV and newspaper pundits?

Sometimes, however, mathematicians' habits of searching for abstraction lead them to make trenchant observations about, say, survival bias, Simpson's paradox, or the unpredictability of nonlinear systems that are unlikely to be made by more traditional commentators. Periodically their deployment of basic arithmetic, even simply about the relative sizes of budget items or causes of death, leads to similarly revealing insights. So at times does an oblique and quirky approach to an issue such as a complexity-theoretic assessment of politicians' speeches or an analysis of Gone with the Wind via systems of differential equations. I'll skip more examples since many such apercus appear in my books (some in A Numerate Life), my columns, and even on twitter (where brevity is at a premium and thus often gives rise to a pithy contest). My focus here is more diffuse.

So, what is a mathematician, myself and others, with aspirations to reach (and perhaps even enlighten) a broader cross-section of people to do? As I've written elsewhere, the philosopher Ludwig Wittgenstein once said that he looked forward to the day when philosophy vanished as a subject but all other subjects were approached philosophically (Pitcher 1965). I have a related but less drastic wish for mathematics. I certainly wouldn't want it to disappear as a subject, but I do wish that it too was more widely seen to be an adverb and that its basic facts, ways of thinking, and informal metaphors could inform our approach to all other subjects, 
including biography. With Wittgenstein's saying as a partial motivation, I have over the years written about the connections between mathematics and humor, journalism, the stock market, analytic philosophy, religion, and a number of other topics. Most of these books have an element of the proverbial parent's insistence that the initially unappetizing liver dish is really the more palatable chicken dinner.

Food analogies aside, mathematics, statistics in particular, is an imperialist discipline that often threatens to assume a dominant role in other disciplines. Nonobvious but significant points of correspondence between mathematics and other endeavors almost always arise if one searches for them. In A Numerate Life I hope to show that there are many such points of correspondence and resonance even between mathematics and biography. A sense of their flavor may be gleaned from the book's table of contents in Table 1, which suggests some of the questions entertained (and hopefully entertaining) in the book, and the short excerpt below.

Needless to add, there are also countless aspects of biography and memoir that are not mentioned in the book, some of which are nevertheless amenable to mathematical analysis. As I've often noted, however, I try in my work to avoid the temptation of "mathism," the mathematical analogue of scientism, an unwarranted exclusive trust in the methods of science. A Numerate Life (whose working title was the perhaps annoying The Book of John 3.14) contains a number of memoiristic vignettes-my early life, school experiences, my grandmother's foibles, my father's influence, meeting my wife, Peace Corps and travels, a modicum of "fame," teaching, etcetera - that do not yield easily, if at all, to the mathematician's arsenal.

These biographical episodes are scattered throughout the book and sometimes serve as jumping-off points for mathematical idealizations of the personal experiences recounted. Parenthetically and more generally, I think an elaboration of this phenomenon (rather than Platonism) helps explain Eugene Wigner's (1960) query about "the unreasonable effectiveness of mathematics." Mathematics, as Bertrand Russell (1917) famously said, has "a beauty, cold and austere," but it springs, I believe, from real lives, warm and messy. Playing in the mud with sticks and stones leads, over time, to geometry and arithmetic.

Finally, humor. I have long defended a Wittgensteinian paraphrase of its pervasive and adverbial nature. I was thus pleased to note in a couple of articles in Numeracy (Grawe 2015, 2017) a focus on the further fleshing out of the underappreciated connection between humor and mathematics, and I assure readers there is a healthy portion size (food again) of wry, silly, and I hope illuminating jokes in A Numerate Life. In addition, of course, there are the overarching self-referential "jokes" whose largely unpredictable trajectories and sequential punchlines constitute all of our lives, whether numerate or not. As with the real numbers so with real life; there are vastly more irrational points than rational ones (more surds than $11 / 3$ 's). This is all the more reason to cherish the latter. 
Table 1

Table of Contents from A Numerate Life: A Mathematician Explores the Vagaries of Life, his Own and Probably Yours

Introduction: What's It All About?

Chapter 1: Bully Teacher, Childhood Math

Some Early Estimates, Speculations

Pedagogy, Vanquishing Blowhards and Opponents, and Monopoly

Of Mothers and Collecting Baseball Cards

A Further Note on Math, Humor, and My Education

Chapter 2: Bias, Biography, and Why We're All a Bit Far-Out and Bizarre

Bias and Mindsets, Statistics and Biography

Despite Normal Appearances, We're All Strange

Misapplications of Mathematics to Everyday Life-A Caveat

Chapter 3: Ambition versus Nihilism

Infinity, Sets, and Immortality

Selves and Absurdity

The Story of "I"-Neurons, Hallucinations, and Gödel

Chapter 4: Life's Shifting Shapes

Primitive Math, Life Trajectories, and Curve Fitting

The Environment as a Pinball Machine, the Quincunx of Life

Biographies and the Texas Sharpshooter

Chapter 5: Moving toward the Unexpected Middle

A Few Touchstone Memories

Lunch, Good Night, and My Parents-Milwaukee in the 1950s

Logic, Jokes, and Adult Life as an Unexpected Punch Line

Memories and Benford's Law

Chapter 6: Pivots-Past to Present

Kovalevsky, Prediction, and My Grandmother's Petty Larceny

Turning Points, Acadia to Kenya

Past Accomplishments versus Present Potential

Chapter 7: Romance among Trans-Humans and Us Cis-Humans

Roboromance and the End of Biography

Choosing a Spouse, Meeting My Wife, Sheila

Romantic Crushes, Bayesian Statistics, and Life

Domestic Math: Toilet Seats, Up or Down; Movies, Early or Late

Chapter 8: Chances Are That Chances Are

If Only . . . Probability and Coincidences, Good, Bad, and Ugly

Innumeracy, A Mathematician Reads the Newspaper, and Their Aftermath

Chapter 9: Lives in the Era of Numbers and Networks

How Many E-Mails, Where Did We Buy That-The Quantified Life

A Twitterish Approach to Biography

Scale and Predictability

Chapter 10: My Stock Loss, Hypocrisy, and a Card Trick My Stock Loss and a Few Pitfalls of Narrative Logic One Cheer for Hypocrisy

Kruskal's Card Trick and Common Denouements

Chapter 11: Biographies: Verstehen or Superficial

Consciousness, Biographies, and Shmata

Leah and Daniel, My Grandsons and I

Gompertz's Law of Human Mortality and Life Span

Chapter 12: Trips, Memories, and Becoming Jaded

Topology, Travel, and a Thai Taxi Driver

Experiencing versus Remembering Selves and Autobiographies

Peak Experiences, Record Setting, and the Path from Jade to Jaded

Joining My Father 


\section{Excerpt from A Numerate Life Despite Normal Appearances, We're All Strange}

Many considerations and perhaps even anodyne personal anecdotes suggest an idea relevant to biographies and the often simplistic way we think of others. Most of us have had the experience of knowing someone superficially and thinking him or her to be quite normal, exemplary even - wonderful family, productive career, publicspirited, and so on. Then, if and when you get closer, you discover that the person is quite bizarre in some ways - not necessarily bad ways, but just very odd ways.

Think perhaps of the popular television series Breaking Bad and the brilliant but poor chemistry teacher and family man dying of cancer who decides to use his expertise to become a manufacturer and distributor of crystal meth. I once was acquainted with someone who appeared to be completely conventional, totally banal, and utterly unimaginative. Then a friend of mine saw him on several occasions gluing five-dollar bills to the sidewalk and then, having retreated a distance from them, giggling at people trying to scrape them off. This is not a confessional book, but, despite being generally quite honest, I do remember a few times sticking a Chuckles candy into a Wisconsin State Journal when I was in college and paying only for the latter. These incongruities bring to mind the quip: There are two kinds of people in the world - those who are very strange and those whom you don't know well.

If by "very strange" or bizarre people, you mean people who, along at least some measurable dimensions, are statistically way off the charts, then this is almost certainly true. "Dimension" can be something geometrical, but needn't be. Think, for example, of dating services that advertise that they check prospective couples for compatibility along dozens of possible dimensions - aspects of personality, unusual obsessions, fears, hobbies, family backgrounds, politics, etcetera. They might consider fifty or more such dimensions.

Or consider people as consumers whose tastes differ along many more dimensions. One can ask whether they prefer one brand of fig bar to another or, more generally, one kind of product to another. We can inquire as well how much they like their fig bar or, more generally, about the intensity of their preferences. Of course, we can also include dimensions of sexual variety, which I'll leave to readers' experiences and imaginations (or to pornhub.com for the unimaginative).

A simple invocation of what's called the multiplication principle in combinatorics is sufficient to demonstrate the number of sexual varieties. Biologically, people can be male, female, or intersex -3 possibilities. They can be attracted to males, females, both, or neither -4 possibilities. And independent of these categories their gender identity may be male, female, androgynous - 3 possibilities. Multiplying 3 by 4 by 3 yields 36 different varieties, all A-OK. Further divisions (involving the ages of the people to whom one is attracted as well as 
various paraphilias) would, of course, increase this number significantly. More generally, products of the numbers of possibilities grow rapidly and lead to huge total numbers of possibilities, not just for sexual variety but also along countless other (collections of) dimensions.

If we define people solely in terms of numbers along these various dimensions, that is, reductively as a collection of atomic traits and as nothing more coherent, then we can more easily understand geometrically why we are all quite strange and far-out. Why exactly?

Toward a geometric understanding of this, imagine a straight line 10 inches long, along which people can be measured on some dimension of interest. Let's consider the parts of the line within $1 / 2$ inch of either end and call it the extreme part of the line. The normal part is the 9-inch middle section, which constitutes 90 percent of the line.

Now consider a square 10 inches on a side, along both of whose dimensions people can be measured. Consider the part within $1 / 2$ inch of a side of this square and call this border area the extreme part of the square. The normal part of the square is the middle section, which constitutes 81.0 percent of the square. This can be seen by noting that the whole square is $10^{2}$ or 100 square inches, and the normal part constitutes only $9^{2}$ or 81 square inches. If you like circles better than squares, realize that the interior of a 10 -inch pizza with a half $1 / 2$-inch crust all around is likewise only 81 percent of the area of the whole pizza. A 1-inch crust leaves only 64 percent for the interior; $8^{2} / 10^{2}=.64$.

Or consider spherical potatoes and my Thanksgiving epiphany. During turkey day preparations recently, I was peeling potatoes in my usual slapdash way and wondered how much of the potato I was wasting. For simplicity's sake I assumed the potatoes were spherical and about 10 centimeters (4 inches) in diameter and that my lazy, sloppy peeling removed about 1 full centimeter from the surface. The peeled potato was thus 8 centimeters in diameter, and the ratio of its volume to that of the unpeeled potato was $512 / 1,000$ (which is $8^{3} / 10^{3}$ ). I was wasting almost half the potato! A disproportionate fraction of its volume was in its periphery.

Next up, let's picture a cube 10 inches on a side, along all three of whose dimensions people can be measured. Consider the part within 1/2 inch of an outside face of this cube and call it the extreme part of the cube. The normal part of the cube is the middle section, which constitutes 72.9 percent of the cube. This can be seen by noting that the whole cube is $10^{3}$ or 1,000 cubic inches, and the normal part constitutes only $9^{3}$ or 729 cubic inches. Returning to Italian food, I note that a similar analysis applies to spherical meatballs.

Although it can't be pictured as easily, the same idea makes sense with higherdimensional hypercubes. Imagine, for example, a four-dimensional hypercube 10 inches on a side, along all four of whose dimensions people can be measured. (Pick your favorite four.) Consider the part within $1 / 2$ inch of the outside of this 
hypercube and call it the extreme part of the hypercube. The normal part of the hypercube is the middle section, which constitutes 65.6 percent of the hypercube. This can again be seen by noting that the whole hypercube is $10^{4}$ or 10,000 cubic inches, and the normal part constitutes only $9^{4}$ or 6,561 cubic inches.

Note that as the number of dimensions increase, the normal part of the hypercube constitutes a smaller and smaller part of the volume of the hypercube in question. We can continue this game and consider not 4 but 50 dimensions along which people can be measured and perform the same sort of calculation. If we do, we'll find that that the interior or normal part of the resulting hypercube constitutes only about $1 / 2$ of 1 percent of the volume of the hypercube. For 100 dimensions, the interior or normal part shrinks to only .0027 percent of the total volume!

And this says what exactly about our abnormality, our strangeness?

Note that most points in the hypercube will be extreme along at least some dimensions and hence will be at the extreme edges of the hypercube. In this same sense (as well as in others), most people live on the extreme, abnormal edges of the human multidimensional hypercube. Vanishingly few of us live in the moderate, normal interior part of the hypercube. Remember that we are defining people reductively as large sets of numbers ranking us along many different dimensions (that is, as points in the hypercube). For the purposes of this exercise each of us can be considered an atomistic collection of preferences, ranging from Prada shoes and Smucker's jelly to investment positions and voting tendencies. (Note, too, that there are surely many more than 50 or 100 dimensions of various sorts along which people can differ and that we can define an extreme score along any given dimension to be one that's even more extreme - as, say, the top and bottom .5 percent rather than the top and bottom 5 percent of the given dimension.)

Once again, if each of us has a score along each of the very many dimensions in a hypercube, then almost all of us will find ourselves to be a point along the edges of the hypercube; that is, an extreme, abnormal point. Nobody except the hopelessly boring and banal live in the moderate, normal interior of the human hypercube.

The same sort of argument can be made in probabilistic terms rather than geometric ones and can also employ the so-called normal distribution (normal is unfortunately a much overused word in mathematics) rather than the uniform, flat distribution I assumed above. Other statistical distributions that lead to even more extreme oddities also exist. Consider an adoptable trait that is slightly unusual or abnormal but only in a statistical sense - say, for example, extended body tattoos. When people consider adopting it, they're influenced by others they know or hear about who have done so, and thus they are marginally more disposed to develop the trait themselves. That creates a cascading effect that results in an "abnormalget-more-abnormal" sort of phenomenon, as the trait and (some of) the people holding it become more and more extreme. This is one reason so-called power law 
distributions (where one quantity varies as the power of another) are so common in social situations and enhance and exaggerate the above geometric strangeness.

I like this little dimensional exercise since it reminds me of the classic book Flatland. The story employs a fictional two-dimensional world of squares and polygons (with a visitor from the third dimension) to make social observations about Victorian culture. A much paler, much reduced bit of social commentary might be squeezed out of the above segment as well, something along the lines of increasing tendency to define ourselves reductively as a mere collection of traits, interests, consumer preferences, and so on.

In any case, given this suggestive little model of multidimensional human beings, it's not really very surprising that there are two kinds of people in the world - those who are very strange and those whom we don't know very well. Once again, almost all of us live in the outer shell of a multidimensional hypercube (or hypersphere or hyper-meatball), whose interior is largely devoid of other humans.

None of this, however, contradicts the observation that there is a broad area of similarity among all people that is described by German mathematician Carl Friedrich Gauss's bell-shaped normal distribution. Whenever we consider traits that depend on many independent factors, the pervasively applicable central limit theorem of statistics tells us these traits will be normally distributed. Along most dimensions people are fairly nondescript and ordinary, even though almost all of us are quite extreme and extraordinary with respect to a good number of other dimensions.

\section{References}

Grawe, Paul H. 2015. "Lewis Carroll and Mathematical Ideals of John Allen Paulos: Review of Alice's Adventures in Wonderland (1865) and Through the Looking-Glass, and What Alice Found There (1871)." Numeracy 10 (2): Article 14. https://doi.org/10.5038/1936-4660.10.2.14

Grawe, Paul H. 2017. "Mathematics and Humor: John Allen Paulos and the Numeracy Crusade." Numeracy 8 (2): Article 11. https:// doi.org/10.5038/1936-4660.8.2.11

Pitcher, George. 1965. "Wittgenstein, Nonsense, and Lewis Carroll." Massachusetts Review 6 (3): 591-611.

Russell, Bertrand. 1917. Mysticism and Logic: And Other Essays. London: George Allen \& Unwin. https://doi.org/10.5962/bhl.title.19117

Wigner, Eugene P. 1965. "The Unreasonable Effectiveness of Mathematics in the Natural Sciences." Communications on Pure and Applied Mathematics 13: 114. https://doi.org/10.1002/cpa.3160130102 